\title{
The Subcultures Network
}

The Subcultures Network formed as the Interdisciplinary Network for the Study of Subcultures, Popular Music and Social Change in 2011. Its inaugural conference was held that year at London Metropolitan University, and since then the Network has organised various panels, seminars and workshops around the UK, in Europe and the United States. In 2013, the Network received an Arts and Humanities Research Council (AHRC) grant to develop its activities, which are shaped around five key aims: to promote and facilitate research exploring the ways in which subcultures and popular music serve as mediums for social change; to encourage interdisciplinary and multidisciplinary approaches to the study of subcultures, popular music and social change; to initiate and sustain a dialogue between scholars whose work focuses on subjects relating to subcultures, popular music and social change by way of regular workshops, symposia and conferences; to provide support and opportunities for peer-review towards funding proposals related to the study of subcultures, popular music and social change; to instigate and amass a significant body of scholarly work examining the relationship between subcultures, popular music and social change.

The Network is open to all and directed by a steering committee that in 2011-13 comprised:

Jon Garland (University of Surrey)

Keith Gildart (University of Wolverhampton)

Anna Gough-Yates (University of West London)

Paul Hodkinson (University of Surrey)

Sian Lincoln (Liverpool John Moores University)

Bill Osgerby (London Metropolitan University)

Lucy Robinson (University of Sussex)

John Street (University of East Anglia)

Peter Webb (Cambridge University)

Matthew Worley (University of Reading)

Information about the Network can be found at:

www.reading.ac.uk/history/research/subcultures

www.facebook.com/groups/17543791954

Contact: m.worley@reading.ac.uk 